\title{
Correction to: Late Holocene palaeovegetational and environmental changes inferred from organic geochemical proxies in sediments from Pookot Lake, southern India
}

\author{
Sandeep Kizhur ${ }^{1,2} \cdot$ Rajasekhariah Shankar ${ }^{1,3} \cdot$ Anish Kumar Warrier ${ }^{1,4} \cdot$ Madhusudan G. Yadava $^{5}$. \\ Rengaswamy Ramesh ${ }^{5} \cdot$ Rashmikant A. Jani $^{5}$
}

Published online: 12 December 2019

(C) Saudi Society for Geosciences 2019

\section{Correction to: Arabian Journal of Geosciences} https://doi.org/10.1007/s12517-019-4813-2

The original version of this paper was published with error. Figures 3 and 7 in the online version of the article happen to be the same. Given in this article are the correct figures.

The original article has been corrected.

The online version of the original article can be found at https://doi.org/ 10.1007/s12517-019-4813-2

Sandeep Kizhur

sandeepk01@gmail.com

1 Department of Marine Geology, Mangalore University, Mangalagangotri, Karnataka 574 199, India

2 Present address: Department of Geology, School of Earth Science Systems, Central University of Kerala, Periye P.O., Tejaswini Hills, Kasaragod, Kerala 671316, India

3 Present address: Bengaluuru, India

4 Present address: Centre for Climate Studies/Department of Civil Engineering (MIT), Manipal Academy of Higher Education, Manipal, Karnataka 576104, India

5 Physical Research Laboratory, Navrangpura, Ahmedabad, Gujarat 380009, India 


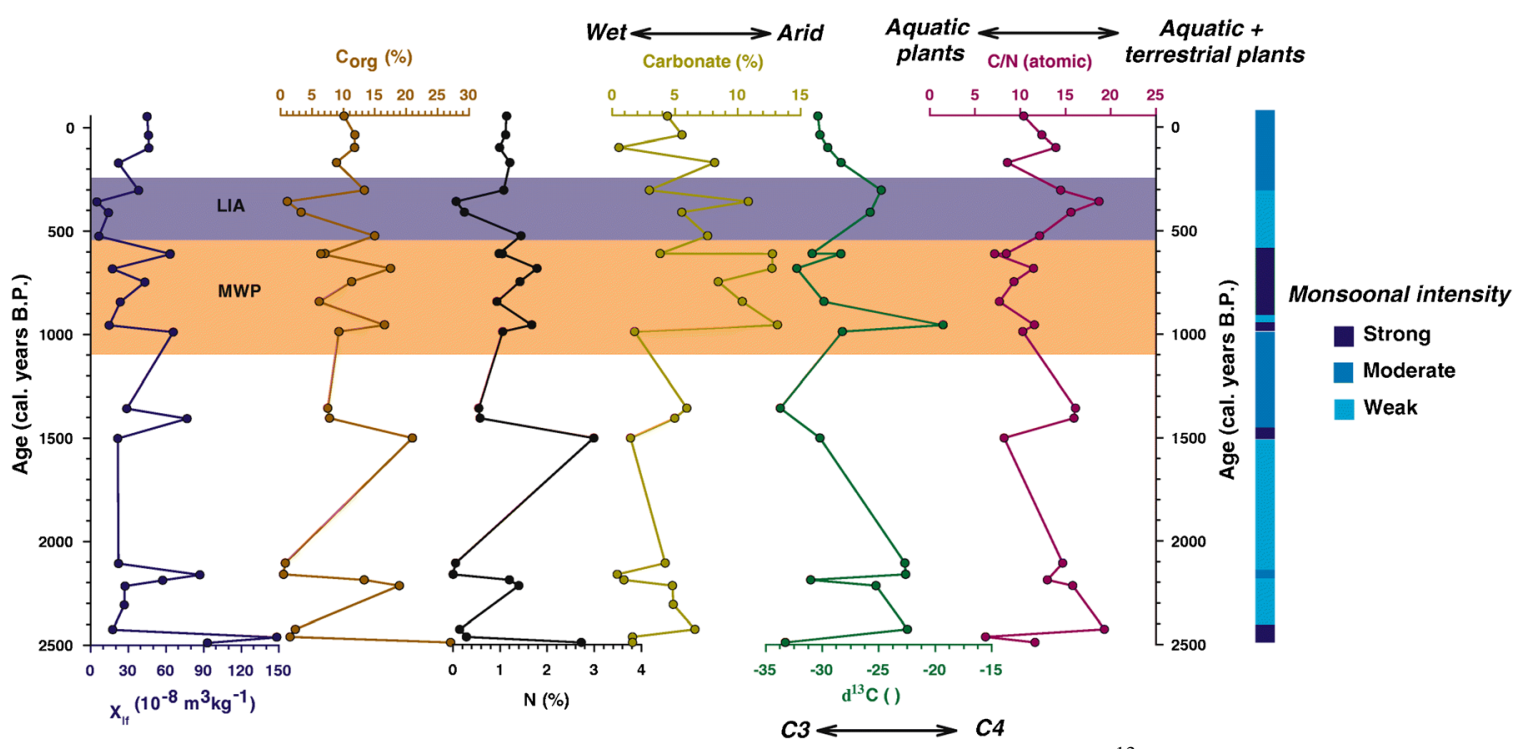

Fig. 3 Down-core variations of magnetic susceptibility $\left(\chi_{1 f}\right)$, organic carbon $\left(\mathrm{C}_{\mathrm{org}}\right)$, nitrogen, carbonate $\%, \delta^{13} \mathrm{C}$ and $\mathrm{C} / \mathrm{N}$ ratio of Pookot Lake sediments Note: $\mathrm{C}_{\text {org }}$ and $\mathrm{N}$ do not exhibit any significant relationship with $\chi_{\mathrm{lf}}$ whereas carbonate, $\mathrm{C} / \mathrm{N}$ ratio and $\delta^{13} \mathrm{C}$ exhibit a negative correlation (LIA, Little Ice Age; MWP, MedievalWarm Period

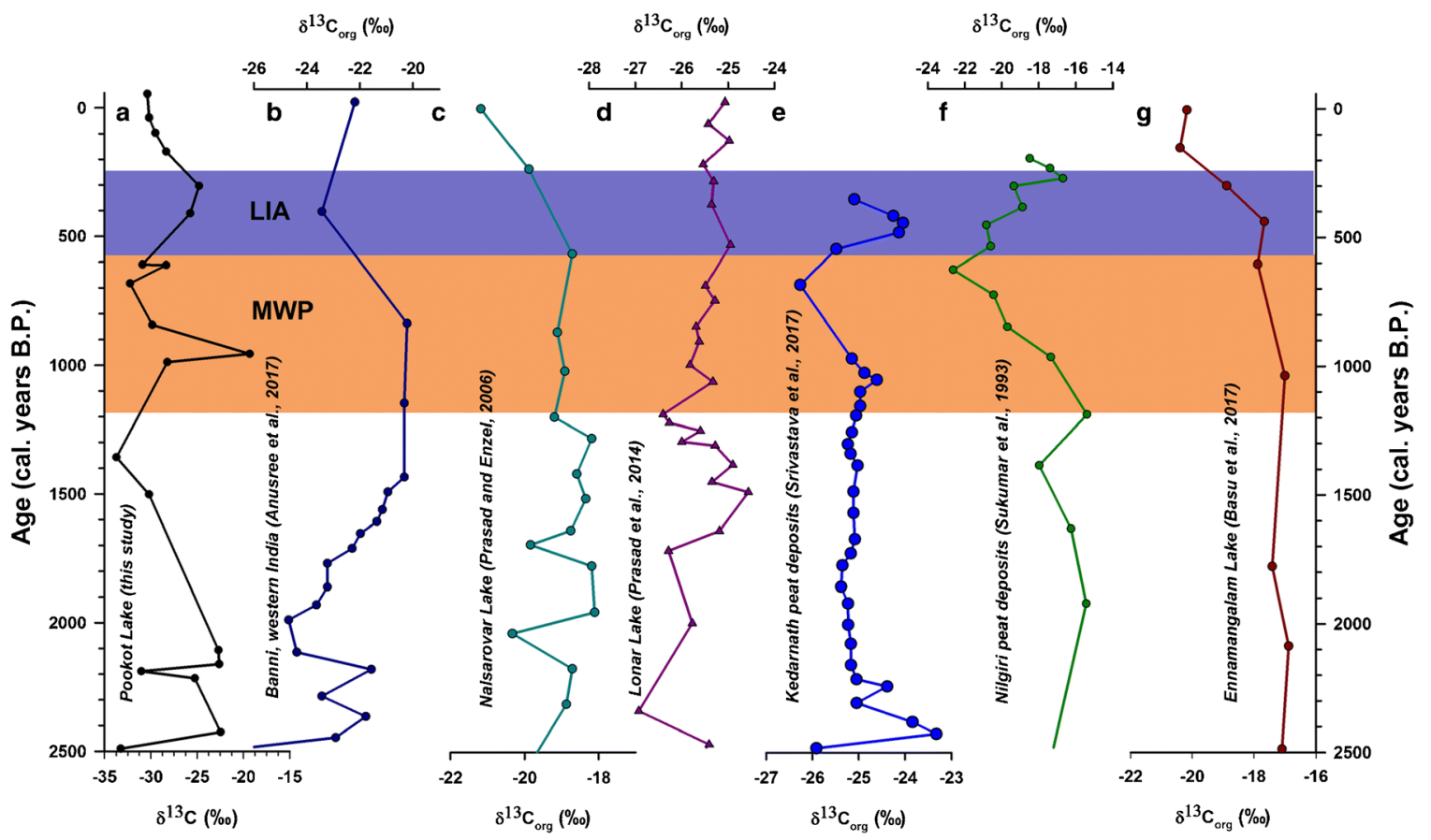

Fig. 7 Comparison of Pookot Lake sediment $\delta^{13} \mathrm{C}$ data with other palaeoclimatic records: (a) Pookot Lake sediments (present study); (b) Banni grassland, Gujarat (Anusree et al. 2017); (c) Nalsarovar lake, western India (Prasad and Enzel 2006); (d) Lonar Lake, Central India (Prasad et al. 2014); (e) Peat from Kedarnath (Srivastava et al. 2017); (f) Nilgiri peat deposits, southern India (Sukumar et al. 1993); and (g) Lake Ennamangalam, Tamilnadu, southern India (Basu et al. 2017) 